\title{
Tonic Control of Peripheral Cutaneous Nociceptors by Somatostatin Receptors
}

\author{
Susan M. Carlton, Junhui Du, Shengtai Zhou, and Richard E. Coggeshall \\ Department of Anatomy and Neurosciences, Marine Biomedical Institute, University of Texas Medical Branch, Galveston, \\ Texas 77555-1069
}

The peptide somatostatin [somatotropin release-inhibiting factor (SRIF)] is widely distributed in the body and exerts a variety of hormonal and neural actions. Several lines of evidence indicate that SRIF is important in nociceptive processing: (1) it is localized in a subset of small-diameter dorsal root ganglion cells; (2) activation of SRIF receptors results in inhibition of both nociceptive behaviors in animals and acute and chronic pain in humans; (3) SRIF inhibits dorsal horn neuronal activity; and (4) SRIF reduces responses of joint mechanoreceptors to noxious rotation of the knee joint. The goal of the present study is to show that cutaneous nociceptors are under the tonic inhibitory control of SRIF. This is accomplished using behavioral and electrophysiological paradigms. In a dose-dependent manner, intraplantar injection of the SRIF receptor antagonist cyclosomatostatin (c-SOM) results in nociceptive behaviors in normal animals and enhancement of nociceptive behaviors in formalin-injected animals, and these actions can be blocked

The peptide somatostatin [somatotropin release-inhibiting factor (SRIF)] is widely distributed in the brain and periphery (Patel, 1992), and it exerts a variety of hormonal and neural actions (Epelbaum, 1986). Our particular interest concerns the role of SRIF in nociception. There are four lines of evidence suggesting that SRIF is important in nociceptive processing. First, SRIF is localized in a subset of small-diameter dorsal root ganglion (DRG) cells (Hökfelt et al., 1975). Second, activation of SRIF receptors results in inhibition of both nociceptive behaviors in animals (Eschalier et al., 1991; Chapman and Dickenson, 1992; Corsi et al., 1997; Carlton et al., 2001) (but see Hitosugi et al., 1999; Kamei et al., 1999) and acute and chronic pain in humans (Chrubasik et al., 1985; Meynadier et al., 1985; Plourde et al., 1993; Taura et al., 1994; Paice et al., 1996). Third, SRIF inhibits dorsal horn neuronal activity (Randic and Miletic, 1978; Miletic and Randic, 1982; Murase et al., 1982; Sandkuhler et al., 1990). Finally, SRIF reduces responses of joint mechanoreceptors to noxious rotation of the cat normal knee joint and to both nonnoxious and noxious rotation in the inflamed knee joint (Heppelmann and Pawlak, 1997). Thus, considerable evidence has accumulated to suggest a role for SRIF in the control of nociception.

Received Nov. 21, 2000; revised March 9, 2001; accepted March 15, 2001.

This work was supported by National Institutes of Health Grants NS11255, NS27910, and NS40700 (to S.M.C.) and NS10161 (to R.E.C.). We thank Vicki Wilson for her excellent secretarial assistance.

Correspondence should be addressed to Dr. Susan M. Carlton, Department of Anatomy and Neurosciences, Marine Biomedical Institute, University of Texas Medical Branch, Galveston, TX 77555-1069. E-mail: smcarlto@utmb.edu.

Copyright (C) 2001 Society for Neuroscience $0270-6474 / 01 / 214042-08 \$ 15.00 / 0$ when c-SOM is coapplied with three different SRIF agonists. Furthermore, intraplantar injection of SRIF antiserum also results in nociceptive behaviors. Electrophysiological recordings using an in vitro glabrous skin-nerve preparation show increased nociceptor activity in response to c-SOM, and this increase is blocked by the same three SRIF agonists. Parallel behavioral and electrophysiological studies using the opioid antagonist naloxone demonstrate that endogenous opioids do not maintain a tonic inhibitory control over peripheral nociceptors, nor does opioid receptor antagonism influence peripheral SRIF effects on nociceptors. These findings demonstrate that SRIF receptors maintain a tonic inhibitory control over peripheral nociceptors, and this may contribute to mechanisms that control the excitability of these terminals.

Key words: primary afferent; nociception; inhibitory peptides; opioid; cutaneous; sensory neurons

The actions of SRIF are mediated by G-protein-coupled receptors, and five SRIF receptors $\left(\mathrm{SST}_{1}-\mathrm{SST}_{5}\right)$ have been cloned (Patel et al., 1995). Anatomical studies localize two of the five SRIF receptors in DRG cells, and these include $\mathrm{SST}_{2 \mathrm{a}}$ (Schulz et al., 1998) and $\mathrm{SST}_{2 \mathrm{~b}}$ (Schindler et al., 1999) subtypes, as well as $\mathrm{SST}_{3}$ (Senaris et al., 1995). Recently, we localized $\mathrm{SST}_{2 \mathrm{a}}$ on peripheral unmyelinated nociceptive fibers at the dermal-epidermal junction in rat glabrous skin (Carlton et al., 2001). The localization of SRIF receptors on peripheral primary afferents provides a peripheral anatomical target for the effective reduction, by SRIF or its agonists, of (1) inflammatory knee pain in humans (Matucci-Cerinic and Marabini, 1998), (2) formalin (FM)-induced nociceptive behaviors in rats (Carlton et al., 2001), (3) responses of mechanoreceptors to noxious knee joint rotation in cats (Heppelmann and Pawlak, 1997) and (4) responses of sensitized nociceptors in rat glabrous skin (Carlton et al., 2001). Furthermore, it has been hypothesized that SRIF maintains a tonic inhibitory control over mechanoreceptors in the knee joint because close arterial injection of an SRIF receptor antagonist increases the afferent discharges that follow noxious joint rotation (Heppelmann and Pawlak, 1999).

That SRIF or its agonists provide effective pain relief when applied locally is clinically important because this route would avoid side effects that accompany systemic activation of SRIF systems. Furthermore, the concept that SRIF and its receptors exert a tonic inhibitory control over joint mechanoreceptors is novel and potentially clinically relevant. If a similar tonic control exists in relation to cutaneous nociceptors, this would imply that the phenomenon is common to nociceptive primary afferents. 
Furthermore, it raises the possibility that a reduction or absence of SRIF might contribute to chronic pain states.

The goal of the present study is to show that cutaneous nociceptors are under the tonic inhibitory control of SRIF. This is accomplished using behavioral and electrophysiological paradigms. Behaviorally, we show that local, peripheral injection of the SRIF receptor antagonist cyclo-somatostatin (c-SOM) or SRIF antiserum results in nociceptive behaviors in normal animals and c-SOM enhances nociceptive behaviors in formalininjected animals. Electrophysiologically, we record from individual nociceptors in a glabrous skin-nerve preparation to correlate changes in nociceptive behaviors with activity of individual nociceptors. Parallel behavioral and electrophysiological studies using the opioid antagonist naloxone demonstrate that endogenous opioids do not maintain a tonic inhibitory control over peripheral nociceptors, nor does opioid receptor antagonism influence peripheral SRIF effects on nociceptors.

\section{MATERIALS AND METHODS \\ SRIF receptor antagonist actions}

\section{Behavioral studies}

Male Sprague Dawley rats $(200-250 \mathrm{gm} ; n=78)$ were used in the behavioral studies. All experiments were approved by the University Animal Care and Use committee and adhered to International Association for the Study of Pain guidelines (Zimmermann, 1983). The animals were housed in groups of three in plastic cages with soft bedding under a reversed $12 \mathrm{hr}$ light/dark cycle. After arrival at the animal care facility, they were acclimated for at least $3 \mathrm{~d}$ before behavioral testing was initiated. The rats were habituated to the behavioral testing procedures by placement on a wire screen platform in Plexiglas cages $(8 \times 8 \times 18$ $\mathrm{cm}$ ) for $1 \mathrm{hr}$. Each rat was habituated twice before being placed in an experimental group.

c-SOM in normal animals. A working dose of the SRIF receptor antagonist c-SOM (Bachem, Torrence, CA) was determined in a doseresponse study. The c-SOM was dissolved in PBS, pH7.4 (Life Technologies, Gaithersburg, MD), animals were injected as described below with $0.013,0.13$, or $1.3 \mathrm{~mm}$ c-SOM or PBS alone $(n=6-7$ per group $)$ in a 30 $\mu \mathrm{l}$ volume, and the number of spontaneous flinches that occurred in 1 or 5 min intervals was determined. A flinch was defined as a spontaneous rapid jerk of the whole foot, whether the foot was on the screen or held in the air.

Blockade of c-SOM-induced activity with SRIF receptor agonists. In separate groups of animals, the specificity of c-SOM for SRIF receptors was assessed by coinjection of $1.3 \mathrm{~mm}$ c-SOM with the SRIF agonists octreotide (OCT) $(20 \mu \mathrm{M} ; n=6$; Sandoz, East Hanover, NJ), vapreotide (VAP) (20 $\mu \mathrm{M} ; n=6$; American Peptide Co., Sunnyvale, CA), or SRIF-14 (10 $\mu \mathrm{M} ; n=7$; Research Biochemicals, Natick, MA) in a $30 \mu \mathrm{l}$ total volume, and numbers of spontaneous flinches were determined.

SRIF antiserum in normal animals. To provide additional evidence that SRIF exerts tonic inhibitory control over peripheral nociceptors, antiserum to SRIF (Chemicon, Temecula, CA) was dissolved in PBS (1:500$1: 1000, \mathrm{pH} 7.4)$ and animals $(n=6)$ were injected with a $30 \mu$ l volume as described below. The number of spontaneous flinches in a $15 \mathrm{~min}$ interval was then determined and compared with flinches in animals receiving PBS alone $(n=6)$ or c-SOM $(n=7)$.

$c-S O M$ in formalin-injected animals. Two groups of rats received intraplantar injections of $1.3 \mathrm{mM} \mathrm{c}-\mathrm{SOM}$ plus $1 \% \mathrm{FM}(n=8)$ or $1 \% \mathrm{FM}$ alone $(n=7)$ in a $30 \mu \mathrm{l}$ volume, and flinching behavior as well as lifting/licking (L/L) behaviors were assessed. Possible systemic effects produced by intraplantar injection of $1.3 \mathrm{~mm}$ c-SOM were behaviorally evaluated after injection of $30 \mu \mathrm{l}$ of $1.3 \mathrm{~mm}$ c-SOM in one hindpaw, followed immediately by injection of $30 \mu \mathrm{l}$ of $1 \%$ FM into the contralateral hindpaw.

Intraplantar injections. Intraplantar injections of c-SOM or SRIF antiserum were performed using a 28 gauge needle attached to a $50 \mu \mathrm{l}$ Hamilton syringe with PE20 tubing. In unanesthetized animals, the needle punctured into the subcutaneous space of the plantar skin just proximal to the footpads and was then guided proximally $0.5 \mathrm{~cm}$ to where the drug was delivered. Each animal was used only once, and the experimenter was unaware of which drug was being injected into each animal.
Behavioral testing. The c-SOM- and anti-SRIF-induced nociceptive responses were quantified by counting the number of flinches of the injected hindpaw in 1 or 5 min intervals, measured for $15-30$ min after injection. Formalin-induced nociception was assessed by quantifying the number of flinches and the number of seconds an animal spent $\mathrm{L} / \mathrm{L}$ the injected paw in $5 \mathrm{~min}$ intervals for $60 \mathrm{~min}$ after injection. There are two phases in FM-induced spontaneous pain behaviors (Dubuisson and Dennis, 1977). The first phase occurs between 0 and $10 \mathrm{~min}$ after FM injection, and the second occurs between 10 and 40 min after FM injection. The data for the phases are reported as the average number of flinches and number of seconds spent L/L per 5 min interval, and the following formulas are used for calculating the average behavior occurring during a phase: (1) first phase, [total number of flinches or $\mathrm{L} / \mathrm{L}$ time]/2 (two 5 min intervals in phase 1); and (2) second phase, [total number of flinches or L/L time]/6 (six 5 min intervals in phase 2).

\section{Electrophysiological studies}

Single-unit recordings from $\mathrm{C}$-mechanoheat $(\mathrm{CMH})$-sensitive fibers were obtained using an in vitro skin-nerve preparation of the glabrous skin (Du et al., 2001). Eighteen male Sprague Dawley rats (200-300 gm) were killed with an overdose of $\mathrm{CO}_{2}$, and the hindpaw glabrous skin was dissected from each animal with the attached medial and lateral plantar nerves. The preparation was placed corium side up in an organ bath and superfused $\left(15 \mathrm{ml} / \mathrm{min}, 34^{\circ} \mathrm{C}\right)$ with an oxygen-saturated, modified synthetic interstitial fluid solution (SIF) (in mM: $123 \mathrm{NaCl}, 3.5 \mathrm{KCl}, 0.7$ $\mathrm{MgSO}_{4}, 2.0 \mathrm{CaCl}_{2}, 9.5 \mathrm{Na}$ gluconate, $1.7 \mathrm{NaH}_{2} \mathrm{PO}_{4}, 5.5$ glucose, 7.5 sucrose, and 10 HEPES, $\mathrm{pH}$ 7.40). The plantar nerves were placed in a separate chamber with a top layer of mineral oil and a bottom layer of SIF. The nerves were desheathed and teased apart on a mirror stage under a dissecting microscope. Small nerve bundles were isolated and repeatedly split with sharpened forceps until single-unit activity was obtained.

Thermal stimulation. A feedback-controlled lamp placed beneath the organ bath supplied radiant heat to the receptive field of each unit. The bottom of the bath was translucent, and the beam was focused through this onto the epidermal surface of the skin. A thermocouple was placed in the corium above the light beam to measure intracutaneous temperature. A standard $10 \mathrm{sec}$ heat ramp was applied to each unit, starting from an adapting temperature of $34^{\circ} \mathrm{C}$ and rising to $47^{\circ} \mathrm{C}\left(47^{\circ} \mathrm{C}\right.$ on the corium side was equivalent to $51^{\circ} \mathrm{C}$ on the epidermal side). The temperature at which the second spike was elicited by the heat stimulus was defined as thermal threshold.

Mechanical stimulation. Calibrated von Frey filaments (Stoelting Inc., Kiel, WI) were used to determine the mechanical threshold for each unit. The filaments were applied to the receptive field on the corium side of the skin starting with filaments delivering relatively small amounts of force. Progressively stronger filaments were applied to the most sensitive area within the receptive field until an action potential could be consistently evoked. The range of von Frey filaments used delivered 0.1-166 $\mathrm{mN}$ of force.

Chemical stimulation. To investigate $\mathrm{CMH}$ responses to various drugs, a small plastic ring ( $5 \mathrm{~mm}$ in diameter) mounted on a micromanipulator was placed over the receptive field of each unit, and the SIF in the ring was replaced with SIF containing the SRIF receptor antagonist c-SOM alone, combinations of c-SOM with OCT, or VAP or the peptide SRIF itself. All drugs dissolved in SIF were buffered to $\mathrm{pH} 7.40$ and 0.05 .

Neurophysiological recordings. Neural activity was recorded using a DAM80 Differential Amplifier (World Precision Instruments, Sarasota, FL) attached to a gold wire electrode, with the reference electrode positioned nearby. Units responding to mechanical probing with a blunt glass rod were studied in detail. Action potentials were analyzed on a Dell computer (Dell Computer Company, Round Rock, TX) with a custom-made template-matching program that allowed discrimination of single-unit activity based on the amplitude and waveform of each action potential (Forster and Handwerker, 1990). Each unit was stimulated electrically $(0.1 \mathrm{msec}$ duration, train frequency of $1 \mathrm{~Hz})$ at the most mechanosensitive site in the receptive field using a Teflon-coated steel electrode (5 M $\Omega$ impedance, $250 \mu \mathrm{m}$ shaft diameter). Conduction velocity was determined from the latency of the action potential and the distance from the stimulation electrode to the recording site (measured in millimeters). Units with a conduction velocity of $<1.6 \mathrm{~m} / \mathrm{sec}$ were classified as $\mathrm{C}$ fibers.

c-SOM effects on nociceptor activity. To investigate whether CMHs are under tonic control of SRIF, SIF in the ring was replaced with an ascending series of c-SOM in concentrations ranging from 0.00013-3.9 
Figure 1. Dose-response relationships. A, Animals receiving an intraplantar injection of $0.13 \mu \mathrm{M}$ or $1.3 \mathrm{mM}$ c-SOM demonstrate significant flinching behavior compared with animals receiving PBS. * indicates a significant difference from PBS group, and + indicates a significant difference between 0.13 and 1.3 mM doses (one way ANOVA; $p<0.05$ ). $B$, The time course of the flinching behavior is presented in $5 \mathrm{~min}$ intervals. Note that the flinching behavior produced by $1.3 \mathrm{~mm}$ c-SOM is blocked by coinjection with OCT. * indicates a significant difference from PBS group (Kruskal-Wallis test; $p<0.05$ ). $C$, Coinjection of c-SOM with $10 \mu \mathrm{M}$ SRIF, 20 $\mu \mathrm{M}$ VAP, or $20 \mu \mathrm{M}$ OCT results in a significant reduction in c-SOM-induced flinching behavior (Kruskal-Wallis test; $p<0.05$ ). $D$, The time course of the flinching behavior is presented in 1 min intervals. ${ }^{*}$ indicates a significant difference from VAP, and + indicates a significant difference from SRIF (Kruskal-Wallis test; $p<0.05$ ).
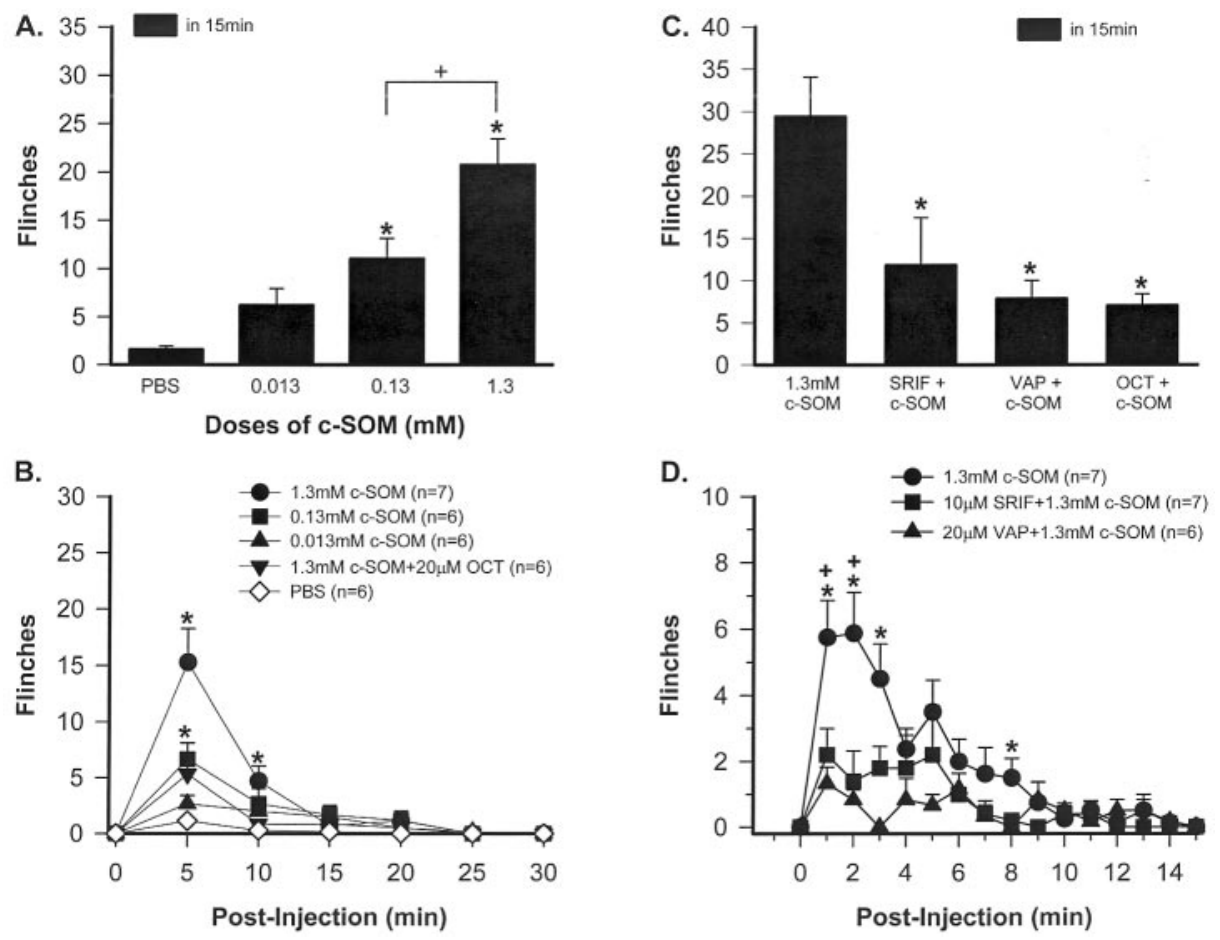

mM made in SIF, $\mathrm{pH} 7.4$, in a dose-response study. Each concentration was applied for $2 \mathrm{~min}$, followed by a $30 \mathrm{sec}$ washout before the next concentration was applied, and the discharge rates of the $\mathrm{CMH}$ units were measured during each application of c-SOM.

c-SOM effects on thermal sensitivity. The dose-response study allowed us to obtain a working dose of c-SOM $(1.3 \mathrm{~mm})$. A separate group of nociceptors was exposed to this dose for $2 \mathrm{~min}$, and the c-SOM-induced activity was analyzed, as well as responses to thermal stimulation before and after c-SOM application.

Blockade of c-SOM-induced activity with SRIF agonists. The specificity of c-SOM for SRIF receptors was assessed by coapplication of the working dose of c-SOM (1.3 mM) with $20 \mu \mathrm{M}$ OCT, $20 \mu \mathrm{M}$ VAP, or $10 \mu \mathrm{M}$ SRIF to the $\mathrm{CMH}$ receptive fields, and changes in discharge rates were then assessed.

\section{Opioid antagonist actions \\ Behavioral studies}

Naloxone in formalin-injected animals. To determine whether opioid receptor antagonism of peripheral nociceptors produced effects similar to that of SRIF receptor antagonism, separate groups of animals $(n=$ 12) received $3 \mu \mathrm{M}$ naloxone plus $2 \% \mathrm{FM}$ or $2 \% \mathrm{FM}$ alone. Flinching and $\mathrm{L} / \mathrm{L}$ behavior were assessed for $40 \mathrm{~min}$ after injection.

\section{Electrophysiological studies}

Naloxone effects on nociceptor activity. To investigate whether $\mathrm{CMH}$ units are under tonic control of opiates, SIF in the ring was replaced with an ascending series of the opiate antagonist naloxone in concentrations ranging from 0.02 to $200 \mu \mathrm{M}$ made in SIF, pH7.4. Each concentration was applied for $2 \mathrm{~min}$, followed by a $30 \mathrm{sec}$ washout before the next concentration was applied, and the discharge rates of the $\mathrm{CMH}$ units were measured before and during each application of naloxone.

Naloxone effects on c-SOM-induced activity. To investigate whether opiates contributed to the c-SOM-induced activity, naloxone $(3 \mu \mathrm{M})$ was coapplied with $1.3 \mathrm{~mm}$ c-SOM to $\mathrm{CMH}$ receptive fields for $2 \mathrm{~min}$, and discharge rates measured before and during drug application.

Statistics. All data are expressed as means \pm SEM and evaluated using the Sigmastat program (Jandel Scientific, Corte Madera, CA). In the behavioral studies, differences between groups were evaluated using a $t$ test if a normality test was passed or using the Kruskal-Wallis test if not. In the electrophysiological studies, differences in discharge rates or threshold temperatures were evaluated with a Friedman's ANOVA, Mann-Whitney $U$ test, or Wilcoxon signed ranks test where appropriate; $p<0.05$ was considered significant.

\section{RESULTS}

\section{SRIF receptor antagonist actions}

\section{Behavioral studies}

c-SOM effects in normal animals. Three different intraplantar doses of c-SOM were given, and flinching behavior was recorded in a dose-response study. Injection of $0.013 \mathrm{~mm}$ c-SOM produced a mild flinching behavior, but this was not significantly different from PBS-induced behavior (Fig. $1 A$ ). In contrast, intraplantar injection of either 0.13 or $1.3 \mathrm{~mm}$ c-SOM resulted in flinching behavior that was significantly increased compared with PBSinduced behavior during the 15 min observation period (one way ANOVA; $p<0.05$ ) (Fig. $1 A$ ).

Blockade of c-SOM-induced activity with SRIF agonists. The increased flinching was blocked if $1.3 \mathrm{~mm}$ c-SOM was coinjected with $20 \mu \mathrm{m}$ OCT (Kruskal-Wallis test; $p<0.05$ ) (Fig. 1B). In addition to OCT, two other SRIF receptor ligands also blocked the c-SOM-induced flinching. Thus, coinjection of $20 \mu \mathrm{M}$ VAP or $10 \mu \mathrm{M}$ SRIF itself also significantly attenuated c-SOM-induced flinching behavior (Kruskal-Wallis test; $p<0.05$ ) (Fig. $1 C$ ). In a more detailed time course, it can be seen that c-SOM-induced flinching is very robust during the first $5 \mathrm{~min}$ after injection and then gradually diminishes to control values by 15 min after injection (Fig. 1D). Note that the flinching behavior in Figure $1 D$ is represented in 1 min intervals, in contrast to Figure $1 B$ in which it is represented in $5 \mathrm{~min}$ intervals. These data indicate that intraplantar injection of the SRIF receptor antagonist c-SOM produces flinching behavior in a dose-dependent manner, and this behavior can be blocked by coinjection of three different SRIF receptor agonists.

SRIF antiserum in normal animals. Intraplantar injection of SRIF antiserum resulted in flinching behavior that was significantly different from animals receiving intraplantar PBS (Kruskal-Wallis test; $p<0.05$ ) but not significantly different from animals injected with $1.3 \mathrm{~mm}$ c-SOM (Fig. 2). These data indicate 


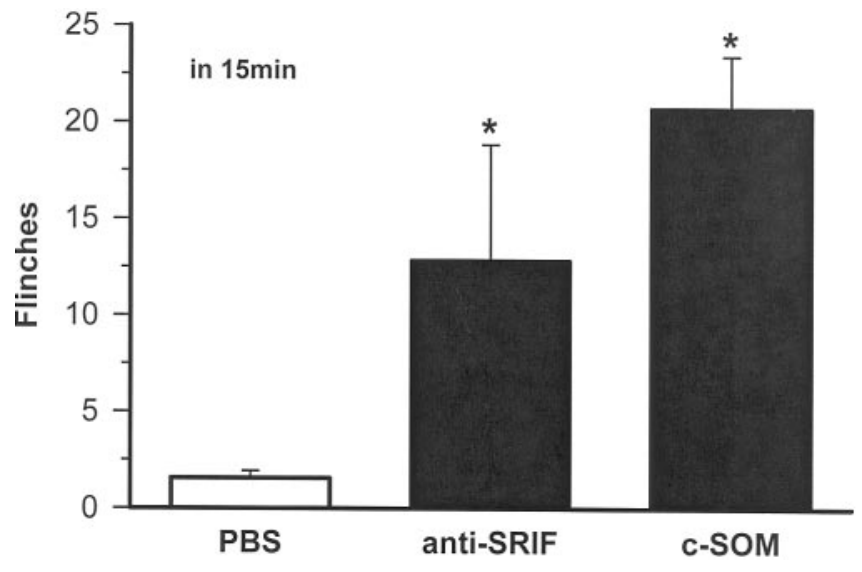

Figure 2. Intraplantar injection of $30 \mu \mathrm{l}$ of SRIF antiserum (1:500$1: 1000 ; n=6)$ or the SRIF antagonist c-SOM $(n=7)$ results in significant flinching behavior compared with animals receiving PBS $(n=6)$. * indicates a significant difference from PBS group (Kruskal-Wallis test; $p<0.05)$.

that intraplantar anti-SRIF results in nociceptive behaviors similar to those induced by c-SOM.

c-SOM in formalin-injected animals. Intraplantar injection of $1 \% \mathrm{FM}$ caused flinching and $\mathrm{L} / \mathrm{L}$ behaviors. A biphasic response was observed with the animals demonstrating these nociceptive behaviors in both phases 1 and 2 (Fig. 3). Compared with 1\% FM alone, rats injected with $1.3 \mathrm{~mm}$ c-SOM plus $1 \%$ FM had significantly increased flinching behavior in phases 1 and 2 and increased $\mathrm{L} / \mathrm{L}$ behaviors in phase 2 (Mann-Whitney $U$ test; $p<$ 0.05 ) (Fig. $3 A, B)$. In the time course study, flinching and $\mathrm{L} / \mathrm{L}$ behavior in the c-SOM plus FM-injected group was elevated at virtually all time points compared with FM alone (Fig. $3 A, B$ ). The animals injected with $1.3 \mathrm{~mm}$ c-SOM in one hindpaw and $1 \%$ FM into the contralateral hindpaw demonstrated nociceptive behaviors similar to animals injected with $1 \% \mathrm{FM}$ alone, indicating that local, peripheral injection of c-SOM did not result in systemic effects (Kruskal-Wallis test; $p<0.05$ ) (Fig. 4A,B).

\section{Electrophysiological studies}

In vitro skin-nerve recordings. Units with conduction velocities below $1.6 \mathrm{~m} / \mathrm{sec}$ that responded to mechanical and heat stimuli were considered $\mathrm{CMH}$ fibers and were included in this study. The mean conduction velocity of these fibers $(n=77)$ was $0.66 \pm 0.03$ $\mathrm{m} / \mathrm{sec}$ and ranged from 0.26 to $1.36 \mathrm{~m} / \mathrm{sec}$. The median force for activation with von Frey filaments was $17.8 \mathrm{mN}$, ranging from 0.45 to $167.6 \mathrm{mN}$. Before each drug application, background activity was measured for $2 \mathrm{~min}$ for each unit, and this activity was subtracted from the activity obtained during the 2 min drug exposure. Before any heat stimulation, background activity was measured for $10 \mathrm{sec}$ for each unit, and this activity was subtracted from the activity obtained during the $10 \mathrm{sec}$ heat stimulus. Units were classified as "responders" if their change in discharge rate was more than the mean \pm 2 SDs of the mean background discharge rate for the total population of fibers studied $(n=77$; mean \pm 2 SD of 0.096 impulses/sec).

c-SOM effects on nociceptor activity. Ascending doses of c-SOM were serially applied to the receptive fields of $\mathrm{CMH}$ units $(n=9$ units from three animals) for 2 min each, with concentrations ranging from 0.00013 to $3.9 \mathrm{~mm}$ c-SOM in a dose-response study. There was no significant change in discharge rates after 0.00013 , 0.0013 , or $0.013 \mathrm{~mm}$ c-SOM. However, mean discharge rates were significantly increased compared with the mean background $(0.03 \pm 0.01 \mathrm{impulses} / \mathrm{sec})$ during exposure to $0.13(0.21 \pm 0.04$ impulses/sec), 0.39 (0.5 \pm 0.23 impulses/sec), $1.3(0.72 \pm 0.34$ impulses/sec), and $3.9 \mathrm{~mm}(0.78 \pm 0.36 \mathrm{impulses} / \mathrm{sec}) \mathrm{c}-\mathrm{SOM}$ (Friedman's ANOVA followed by Dunn's post hoc test; $p<0.01$ ) (Fig. 5A,B). These discharge rates represented 600, 1567, 2300, and $2500 \%$ increases above background, respectively. Based on these findings, $1.3 \mathrm{~mm}$ c-SOM was chosen as the working concentration for the subsequent studies testing c-SOM effects on thermal sensitivity and with different SRIF agonists.

c-SOM effects on thermal sensitivity. A separate population of nociceptors ( $n=18$ units from four animals) was exposed to 1.3 mM c-SOM for $2 \mathrm{~min}$, and changes in unit discharge activity and responses to thermal stimulation were assessed. Application of c-SOM resulted in the generation of action potentials that started $\sim 50 \mathrm{sec}$ after placing the c-SOM in the well, and this activity usually persisted for at least 2 min after the c-SOM was washed away (Fig. 6). The mean discharge rate for the total population $(n=18)$ was significantly increased from $0.06 \pm 0.01$ to $0.17 \pm$ 0.04 impulses/sec (Wilcoxon signed rank test; $p<0.01$ ), and 8 of $18(44 \%)$ were considered c-SOM responders based on the criteria stated above. A $10 \mathrm{sec}$ thermal stimulus applied to the c-SOM responders before and after the c-SOM did not produce a significant change in the heat response (Wilcoxon signed rank test; $p=$ 0.44; data not shown).

Blockade of c-SOM-induced activity with SRIF agonists. Coapplication of $20 \mu \mathrm{M}$ OCT with $1.3 \mathrm{mM} \mathrm{c-SOM}$ to the receptive field of CMH units ( $n=12$ units from three animals) resulted in a blockade of c-SOM-induced activity. The mean discharge rate of these units was $0.02 \pm 0.02$ impulses/sec compared with $0.11 \pm$ $0.04 \mathrm{impulses} / \mathrm{sec}$ for units exposed to c-SOM alone, representing a $79 \%$ decrease in activity (Mann-Whitney rank sum test; $p<$ 0.05 ) (Figs. $7 B, 8$ ). Coapplication of $10 \mu \mathrm{M}$ SRIF with $1.3 \mathrm{~mm}$ c-SOM ( $n=9$ units from two animals) for 2 min also resulted in a significant blockade of c-SOM-induced activity (Mann-Whitney $U$ test; $p<0.05$ ) (Fig. $7 B$ ). The mean discharge rate of these units was $0.01 \pm 0.01 \mathrm{impulses} / \mathrm{sec}$ compared with $0.11 \pm 0.04$ impulses/sec for the c-SOM group, representing a $90 \%$ decrease. Coapplication of $20 \mu \mathrm{M}$ VAP with $1.3 \mathrm{~mm}$ c-SOM resulted in a reduction in c-SOM-induced activity to $0.05 \pm 0.02$ impulses/sec; however, this activity was not significantly different from the activity produced by c-SOM alone (Fig. $7 B$ ).

\section{Opioid antagonist actions}

\section{Behavioral studies}

Naloxone in formalin-injected animals. The data presented here indicate that SRIF receptors maintain a tonic inhibitory control over peripheral nociceptors. To determine whether opiate receptors maintain a similar tonic control, behavioral experiments were performed with naloxone, a potent antagonist of $\mu, \kappa$, and $\delta$ opiate receptors. These studies demonstrate that intraplantar injection of $3 \mu \mathrm{M}$ naloxone $(30 \mu \mathrm{l})$, followed $5 \mathrm{~min}$ later by $2 \% \mathrm{FM}$ $(15 \mu \mathrm{l})$, does not result in a significant change in FM-induced flinching or L/L behavior ( $t$ test) (Fig. 9).

\section{Electrophysiological studies}

Naloxone effects on nociceptor activity. Using the skin-nerve preparation, naloxone was applied for $2 \mathrm{~min}$ in an ascending series of concentrations consisting of $0.2,2.0,20$, and $200 \mu \mathrm{M}$ to eight $\mathrm{CMH}$ units from two animals. Mean background activity was 0.029 impulses/sec, and there was no significant change in this background activity after any dose of naloxone (Friedman's 
Figure 3. A time course study demonstrating that coinjection of $1.3 \mathrm{~mm}$ c-SOM with $1 \%$ FM significantly enhances flinching $(A)$ and lifting/licking behaviors $(B)$. * indicates a significant difference from $1 \%$ FM (MannWhitney $U$ test; $p<0.05$ ).
A.

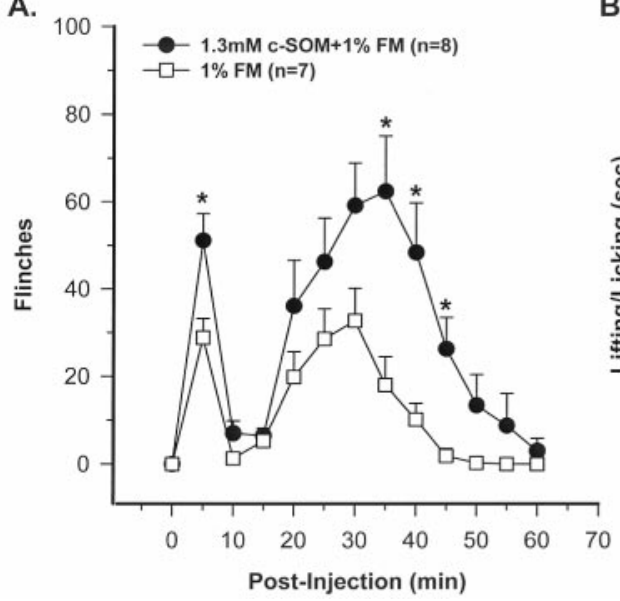

B.

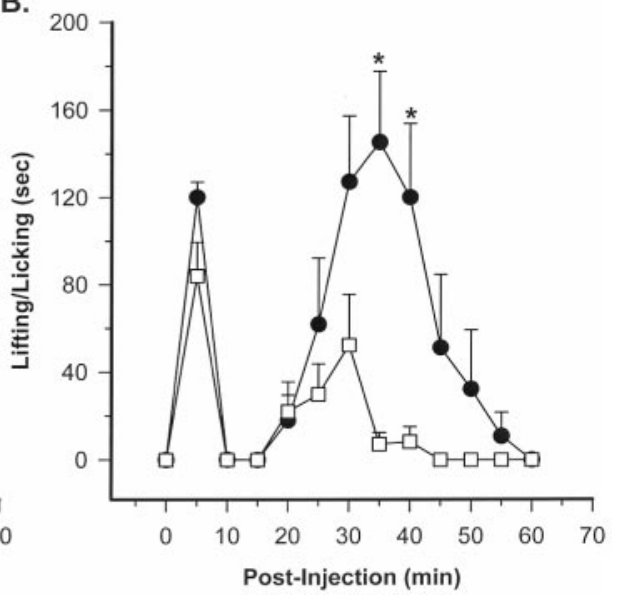

ANOVA; $p=0.34$ ) (Fig. 10A). These findings indicate that opiates do not maintain a tonic control over peripheral nociceptors.

Naloxone effects on c-SOM-induced activity. In a separate population of nociceptors ( $n=10$ from two animals), $2 \mu \mathrm{M}$ naloxone was coapplied with $1.3 \mathrm{~mm}$ c-SOM for $2 \mathrm{~min}$. In this group, the increase in discharge rate $(0.07 \pm 0.02)$ was not significantly different from that group of fibers receiving c-SOM alone $(0.11 \pm$ 0.04; Wilcoxon signed rank test; $p=0.77$ ) (Fig. 10B). Furthermore, the ratio of c-SOM responders in this group of 4 of 10 (40\%) was similar to the 8 of 18 ratio (44\%) obtained in the group receiving c-SOM alone. These data indicate that endogenous opiate peptides and opiate receptors did not contribute the c-SOM-induced effects.

\section{DISCUSSION}

The present study shows that peripheral administration of the SRIF receptor antagonist c-SOM or an antiserum to SRIF itself produces nociceptive behavior in otherwise normal animals. Furthermore, c-SOM enhances formalin-induced nociceptive behaviors and produces a dose-dependent increase in the discharge rates of $\mathrm{CMH}$ fibers in an in vitro skin-nerve preparation. The effects of c-SOM are reversed by administration of either SRIF or the SRIF receptor agonists OCT and VAP. This peripheral
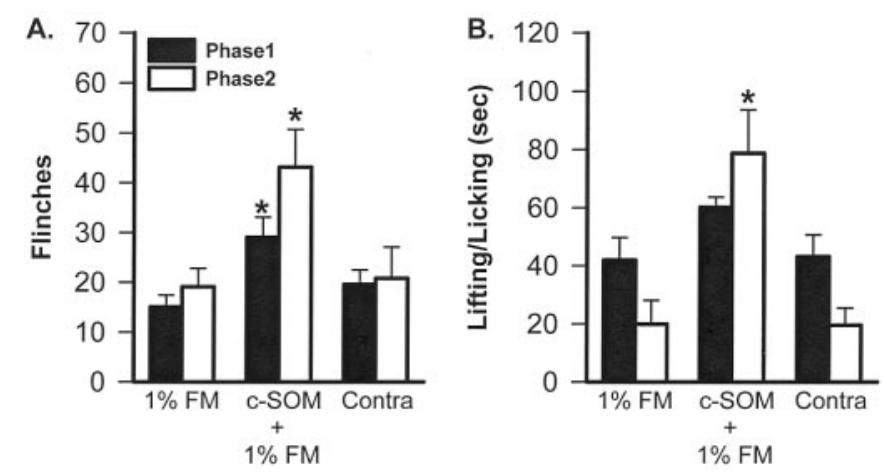

Figure 4. Analysis of the phase 1 and $2 \mathrm{FM}$ data indicates that, compared with FM alone $(n=7)$, c-SOM plus FM $(n=8)$ enhances phases 1 and 2 flinching $(A)$ and phase $2 \mathrm{~L} / \mathrm{L}$ behavior $(B)$. The c-SOM effect is not attributable to a systemic effect because animals injected with $1.3 \mathrm{~mm}$ $\mathrm{c}-\mathrm{SOM}$ in one hindpaw and 1\% FM into the contralateral hindpaw (Contra; $n=7)$ had nociceptive behaviors no different from those seen in animals injected with FM alone. * indicates a significant difference from the $1 \%$ FM group (Kruskal-Wallis test; $p<0.05$ ).
SRIF-induced inhibitory effect is independent of opioid systems because antagonism of peripheral opioid receptors with naloxone does not produce similar behavioral or physiological effects or change the c-SOM effects.

The most likely site of action of intraplantar c-SOM is SRIF receptors on peripheral primary afferents. Immunohistochemical studies localize $\mathrm{SST}_{2 \mathrm{a}}$ and $\mathrm{SST}_{2 \mathrm{~b}}$, and in situ hybridization studies

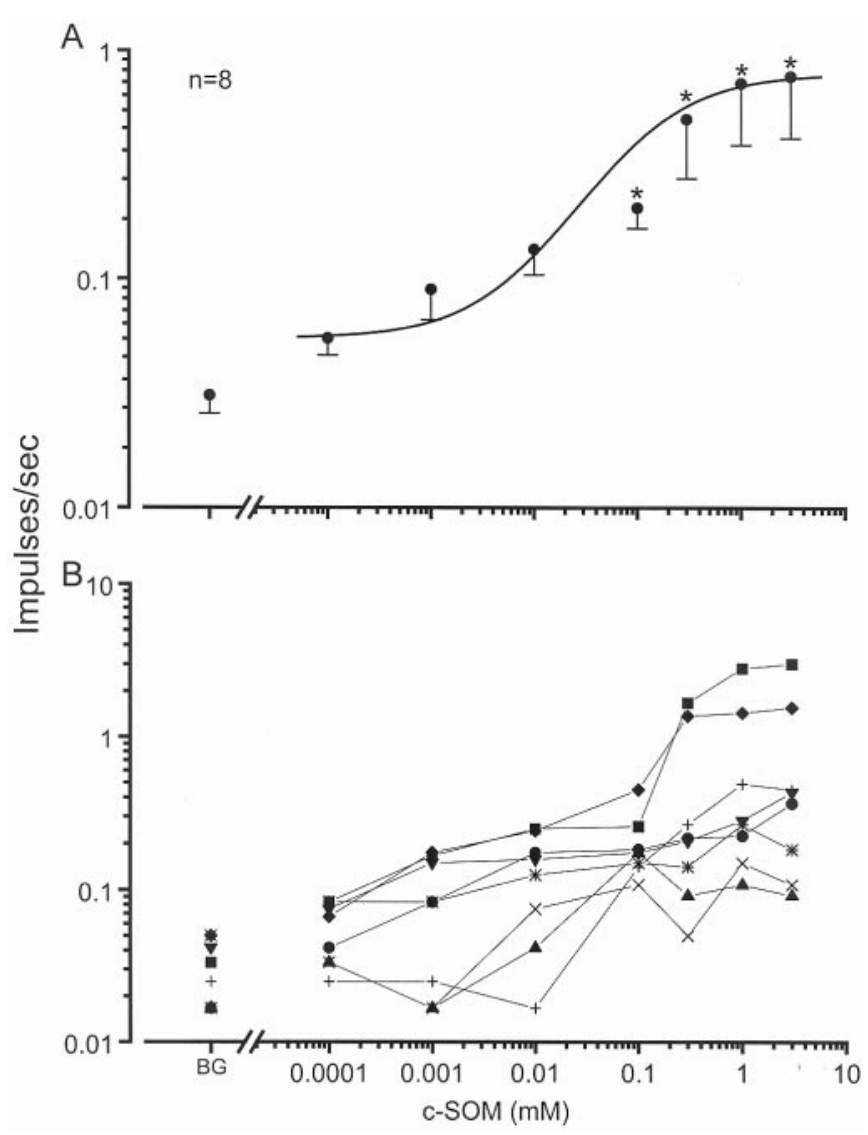

Figure 5. Dose-response relationships. A, Application of c-SOM to the receptive field of nociceptors produces an increase in their discharge rate. An ascending series of c-SOM concentrations, ranging from 0.00013 to 3.9 $\mathrm{mM}$, was applied for $2 \mathrm{~min}$ to the receptive fields of $\mathrm{CMH}$ units, and unit activity was recorded. * indicates significant difference from background $(B G$; Friedman's ANOVA followed by a Dunn's post hoc analysis; $p<$ $0.05)$. $B$, Responses of the individual fibers at each dose. 


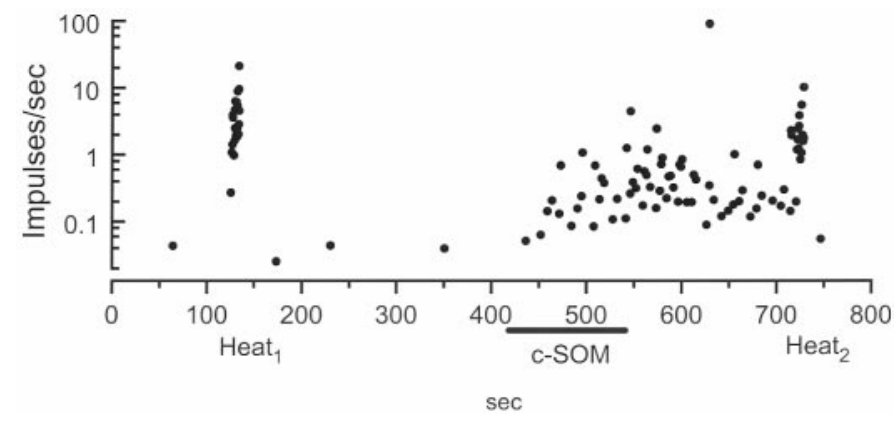

Figure 6. Demonstration of the increase in discharge rate in a $\mathrm{CMH}$ fiber after application of $1.3 \mathrm{~mm}$ c-SOM for 2 min to its receptive field. c-SOM produced no change in heat sensitivity, indicating that it did not sensitize the nociceptor to heat (compare Heat ${ }_{1}$ with Heat ${ }_{2}$ ).

localize mRNA for $\mathrm{SST}_{3}$ in DRG cells (Senaris et al., 1995; Schulz et al., 1998; Schindler et al., 1999). Confirming these primary afferent localizations, immunohistochemical studies have demonstrated that $11 \%$ of unmyelinated sensory axons, presumably nociceptors, at the dermal-epidermal junction in the glabrous skin are positively labeled for $\mathrm{SST}_{2 \mathrm{a}}$ (Carlton et al., 2001). Although SRIF receptors are widespread in the CNS (Uhl et al., 1985) and peripheral tissues (Patel, 1992; Selmer et al., 2000), control experiments in the behavioral studies demonstrate that the site of action of the c-SOM is local in the hindpaw because c-SOM administered in one hindpaw and FM in the contralateral hindpaw results in nociceptive behaviors that are no different from that observed in animals injected with FM alone.

As to the behavioral findings, this is the first report showing that antagonism of peripheral SRIF receptors leads to signs of nociception (flinching of the injected hindpaw) in otherwise normal animals and enhancement of nociceptive behaviors in formalin-injected animals. We believe that these effects are specific to antagonism of SRIF receptors and not attributable to nonspecific activation or irritation of the nociceptors, because two different substances, c-SOM and SRIF antiserum, cause flinching behavior and three different SRIF receptor agonists, SRIF, OCT, and VAP, attenuate or completely block c-SOMinduced flinching. We hypothesize that c-SOM acts by blocking SRIF receptors (but see Siehler and Hoyer, 1999) and that the SRIF antiserum forms a complex with the endogenous SRIF peptide, essentially preventing the interaction of the natural ligand with its receptor. Both of these manipulations will result in flinching behaviors, presumably because of interference with SRIF-induced inhibition of nociceptors.

These data are consistent with the localization of SRIF receptors in DRG cells (Senaris et al., 1995; Schulz et al., 1998; Schindler et al., 1999) and on peripheral nociceptors (Carlton et al., 2001). If it is accepted that the behavioral changes are the result of antagonizing peripheral SRIF receptors, possibly $\mathrm{SST}_{2}$ (Carlton et al., 2001), then the parsimonious hypothesis is that endogenous SRIF tonically activates SRIF receptors on nociceptors, keeping nociceptors tonically inhibited. When this SRIF receptor activation is prevented or reduced by an SRIF receptor antagonist such as c-SOM or SRIF antiserum, nociceptive behavior (flinching) results. However, we cannot completely rule out the possibility that c-SOM-induced nociceptive behaviors might be through indirect mechanisms, such as promotion of proinflammatory cytokines (ten Bokum et al., 2000) or blood flow changes (Chatila et al., 2000). However, c-SOM produces significant ac-
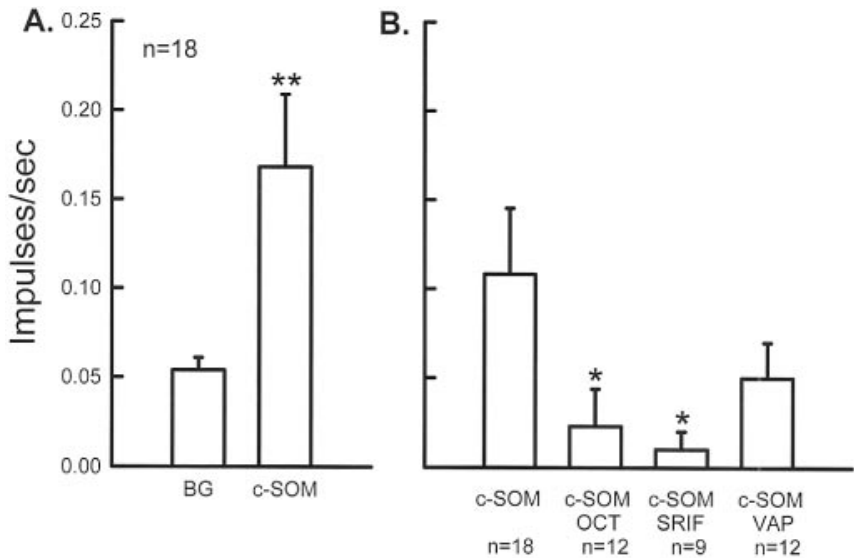

Figure 7. A, Application of $1.3 \mathrm{~mm} \mathrm{c}-\mathrm{SOM}$ to the receptive field of $\mathrm{CMH}$ fibers $(n=18)$ produced a significant increase in their discharge rate. $* *$ indicates a significant difference from background (Wilcoxon signed ranks test; $p<0.01)$. B, c-SOM-induced activity is significantly blocked by coapplication of $20 \mu \mathrm{M}$ OCT or $20 \mu \mathrm{M}$ SRIF and attenuated by $20 \mu \mathrm{M}$ VAP (background activity has been subtracted in each group). * indicates a significant decrease compared with c-SOM alone (Mann-Whitney $U$ test; $p<0.05)$.

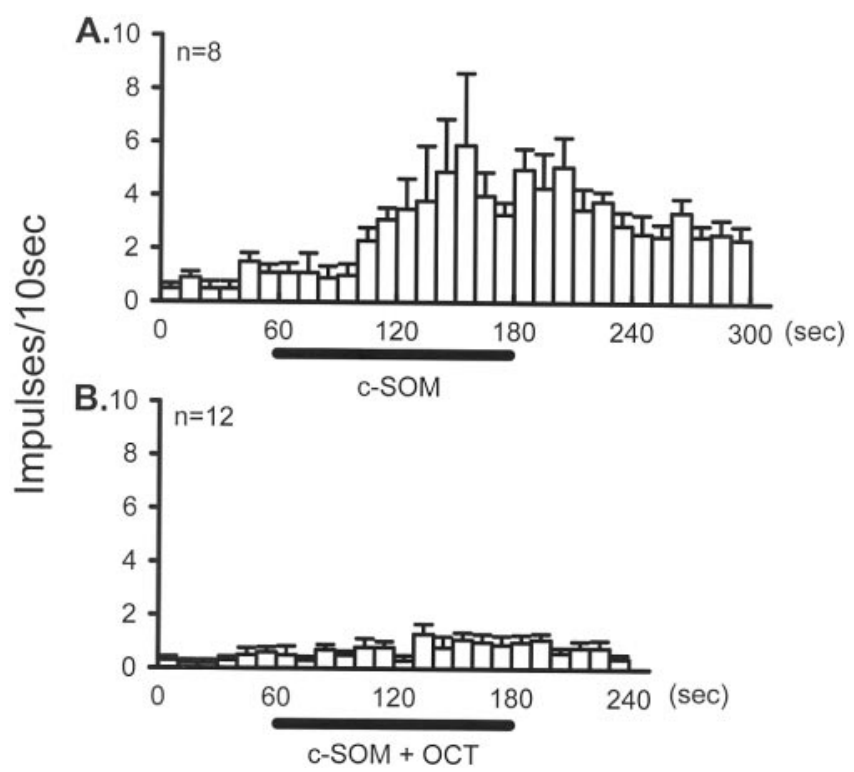

Figure 8. The time course of the mean activity of $\mathrm{CMH}$ units that met the criteria for c-SOM responders. (Responders showed an increase in their discharge rate that was greater that the mean \pm 2 SDs of the total population.) $A$, Application of c-SOM for 2 min resulted in a significant increase in neural activity. $B$, In a separate population, OCT applied in the presence of c-SOM prevented this increase in activity.

tivity in nociceptors in the in vitro skin-nerve preparation in which there is no blood flow; thus, blood flow changes are an unlikely possibility.

More precise evaluations of the effects of SRIF receptor antagonism on peripheral nociceptors are obtained by single afferent fiber recordings in the skin-nerve preparation. Application of c-SOM to the receptive field of $\mathrm{CMH}$ fibers results in an increase in discharge rate in 8 of 18 fibers. It is highly likely that this effect is mediated by SRIF because, as also shown in the behavioral paradigm, three different SRIF receptor agonists attenuate or prevent the c-SOM-induced neural activity. These data provide a physiological correlate for the behavioral changes, demonstrating 

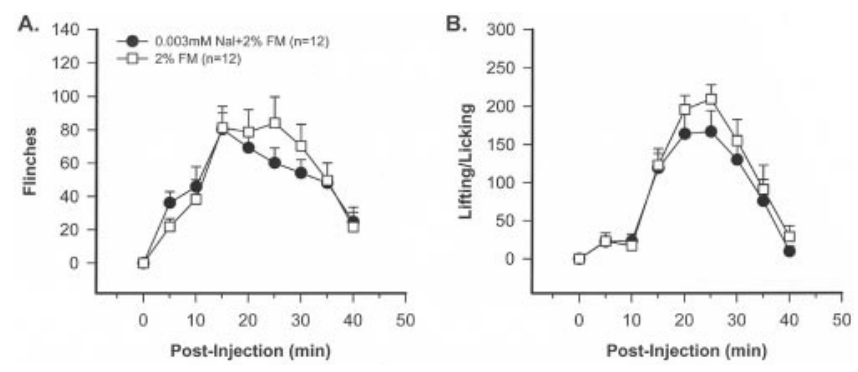

Figure 9. A time course study demonstrating that coinjection of $3 \mu \mathrm{M}$ naloxone ( $\mathrm{Nal}$ ) with $2 \% \mathrm{FM}$ does not enhance flinching behavior $(A)$ or lifting/licking behaviors $(B)$, indicating that, in contrast to SRIF receptor, opioid receptors do not maintain a tonic inhibitory control over peripheral nociceptors ( $t$ test; not significant).

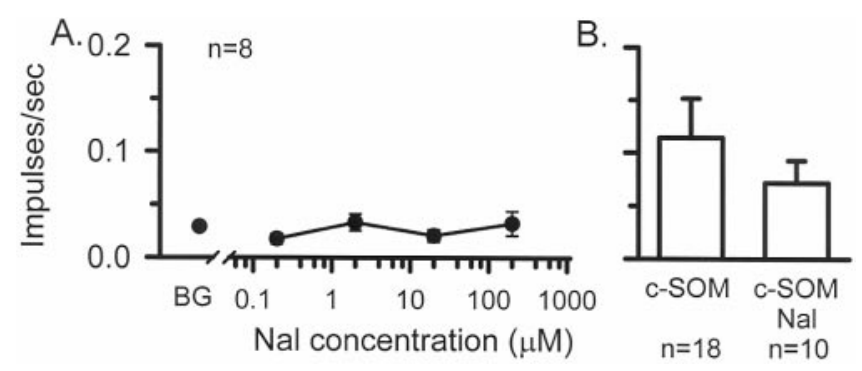

Figure 10. A, Dose-response relationship. Naloxone ( $\mathrm{Nal}$ ), ranging from 0.2 to $200 \mu \mathrm{M}$, was applied for $2 \mathrm{~min}$ to the receptive fields of $\mathrm{CMH}$ units $(n=8)$, and unit activity was recorded. Compared with background $(B G)$, there was no significant change in neural activity in the presence of naloxone, indicating that opioid receptors do not maintain a tonic inhibitory control over CMH fibers (Friedman's ANOVA; $p=0.34$ ). $B$, Compared with c-SOM alone, there was no difference in discharge rate when $2 \mu \mathrm{M}$ naloxone was coapplied with c-SOM (Mann-Whitney $U$ test; $p=0.77)$.

that blockade of peripheral SRIF receptors results in activity in cutaneous nociceptors, thus providing another line of evidence supporting the hypothesis that SRIF receptor activation maintains a tonic inhibitory control of cutaneous nociceptors.

The cellular actions of SRIF are complex, but a major feature of SRIF receptor activation is inhibition of cAMP and $\mathrm{Ca}^{2+}$ currents (Meriney et al., 1994; Tentler et al., 1997) and opening of an inwardly rectifying $\mathrm{K}^{+}$channel (Inoue et al., 1988). In relation to DRG cells, SRIF has been shown to decrease $\mathrm{Ca}^{2+}$ current conductance (Gammon et al., 1990; Taddese et al., 1995). Calcium channel inactivation is known to interfere with the release of peptides and, in this regard, SRIF has been shown to have an anti-inflammatory action (Karalis et al., 1994; Helyes et al., 1996; Szolcsányi et al., 1998a,b), presumably because it prevents release of the proinflammatory peptides substance P (Gazelius et al., 1981; Lembeck et al., 1982) and calcitonin gene-related peptide (Green et al., 1992). Given our behavioral and single fiber findings, it is reasonable to suggest that endogenous SRIF keeps some $\mathrm{Ca}^{2+}$ channels inactivated tonically and, when this tonic action is removed, these inactivated $\mathrm{Ca}^{2+}$ channels open and nociceptors are depolarized. If this action results in a significant increase in intracellular $\mathrm{Ca}^{2+}$, then it is possible that secondmessenger systems are activated and sensitization of nociceptors could occur. The data indicate, however, that sensitization to thermal stimuli does not occur.

In addition to the somatostatinergic system, the opioids constitute another well studied inhibitory system. It has long been debated whether endogenous opioid systems tonically modulate responses to noxious input. Naloxone is the most widely used opioid receptor antagonist. The results of numerous studies in normal or inflamed animals and humans after systemic, intrathecal, or intracerebroventricular naloxone are variable and range from no effect to producing hyperalgesia, analgesia, or biphasic effects (for review, see Kayser et al., 1988). Studies of intraplantar or intra-articular naloxone to determine whether endogenous opioids suppress afferent activity in the inflamed state are disparate in that local naloxone either produces no effect (Schepelmann et al., 1995) or analgesia (Rios and Jacob, 1983). Because of these discrepancies, we determined the effects of intraplantar naloxone on FM-induced nociception and $\mathrm{CMH}$ activity. Although a higher concentration of FM is used in the naloxone plus FM studies (2\%) compared with the c-SOM plus FM studies (1\%), we have shown previously that nociceptive behaviors resulting from intraplantar injection of $2 \% \mathrm{FM}$ can be enhanced (Carlton et al., 1999), so there is little likelihood that a "ceiling effect" occurred in these naloxone studies. Accordingly, local injection of naloxone does not enhance FM-induced nociceptive behaviors, nor does naloxone applied to the receptive fields of primary afferents result in increases in discharge rates. Thus, unlike SRIF, there is no indication that endogenous opioids maintain a tonic inhibitory control over peripheral primary afferents in these models.

There are also suggestions that SRIF or its agonists exert their effects at least partially by activating opioid receptors (Terenius, 1976; Pugsley and Lippmann, 1978; Maurer et al., 1982), although naloxone has no effect on responses of dorsal horn cells to SRIF application (Randic and Miletic, 1978; Sandkuhler et al., 1990) and no effect on the analgesia provided by epidural application of SRIF in humans (Chrubasik et al., 1984, 1985). In the present study, naloxone does not enhance c-SOM-induced activity in nociceptors. Thus, there is no evidence that opiate receptor activation contributes to SRIF receptor-induced effects in this in vitro preparation.

In conclusion, the present study provides several lines of evidence that SRIF and its receptors exert a tonic inhibitory control over cutaneous nociceptors. A similar inhibitory control is also seen in joint mechanoreceptors (Heppelmann and Pawlak, 1999), and so tonic SRIF control of nociceptors is likely to be a widespread phenomenon. If peripheral SRIF tonically inhibits nociceptors, then this may contribute to control of nociceptor responsiveness. Accordingly, disruption or decreases in the peripheral somatostatinergic system may increase the responsiveness of peripheral nociceptors, perhaps being a mechanism contributing to certain chronic pain states. The dissociation between the peripheral opioid and somatostatinergic systems suggests that SRIF receptor activation might be beneficial in pain patients in which opioids either do not ameliorate the pain or have lost their effectiveness. Controlling the SRIF system by manipulating endogenous SRIF might alleviate pain in acute and chronic conditions, particularly when opioids do not provide satisfactory analgesia.

\section{REFERENCES}

Carlton SM, Zhou S, Coggeshall RE (1999) Peripheral GABA receptors: evidence for peripheral primary afferent depolarization. Neuroscience 93:713-722.

Carlton SM, Du J, Davidson E, Zhou S, Coggeshall RE (2001) Somatostatin receptors on peripheral primary afferent terminals: inhibition of sensitized nociceptors. Pain 90:233-244.

Chapman V, Dickenson AH (1992) The effects of sandostatin and somatostatin on nociceptive transmission in the dorsal horn of the rat spinal cord. Neuropeptides 23:147-152. 
Chatila R, Ferayorni L, Gupta T, Groszmann RJ (2000) Local arterial vasoconstriction induced by octreotide in patients with cirrhosis. Hepatology 31:572-576.

Chrubasik J, Meynadier J, Blond S, Scherpereel P, Ackerman E, Weinstock M, Bonath K, Cramer H, Wunsch E (1984) Somatostatin, a potent analgesic. Lancet 2:1208-1209.

Chrubasik J, Meynadier J, Scherpereel P, Wunsch E (1985) The effect of epidural somatostatin on postoperative pain. Anesth Analg 64:1085-1088.

Corsi MM, Ticozzi C, Netti C, Fulgenzi A, Tiengo M, Gaja G, Guidobono F, Ferrero ME (1997) The effect of somatostatin on experimental inflammation in rats. Anesth Analg 85:1112-1115.

Du J, Koltzenburg M, Carlton SM (2001) Glutamate-induced excitation and sensitization of nociceptors in rat glabrous skin. Pain 89:187-198.

Dubuisson D, Dennis SG (1977) The formalin test: a quantitative study of the analgesic effects of morphine, meperidine, and brain stem stimulation in rats and cats. Pain 4:161-174.

Epelbaum J (1986) Somatostatin in the central nervous system: physiology and pathological modifications. Prog Neurobiol 27:63-100.

Eschalier A, Aumaitre O, Ardid D, Fialip J, Duchene-Marullaz P (1991) Long-lasting antinociceptive effect of RC-160, a somatostatin analog, in mice and rats. Eur J Pharmacol 199:119-121.

Forster C, Handwerker HO (1990) Automatic classification and analysis of microneurographic spike data using a PC/AT. J Neurosci Methods 31:109-118.

Gammon CM, Lyons SA, Morell P (1990) Modulation by neuropeptides of bradykinin-stimulated second messenger release in dorsal root ganglion neurons. Brain Res 518:159-165.

Gazelius B, Brodin E, Olgart L, Panopoulos P (1981) Evidence that substance $\mathrm{P}$ is a mediator of antidromic vasodilatation using somatostatin as a release inhibitor. Acta Physiol Scand 113:155-159.

Green PG, Basbaum AI, Levine JD (1992) Sensory neuropeptide interactions in the production of plasma extravasation in the rat. Neuroscience 50:745-749.

Helyes Z, Pintér E, Szolcsányi J, Horvath J (1996) Anti-inflammatory and antinociceptive effect of different somatostatin-analogs. Neurobiology 4:115-117.

Heppelmann B, Pawlak M (1997) Inhibitory effect of somatostatin on the mechanosensitivity of articular afferents in normal and inflamed knee joints of the rat. Pain 73:377-382.

Heppelmann B, Pawlak M (1999) Peripheral application of cyclosomatostatin, a somatostatin antagonist, increases the mechanosensitivity of rat knee joint afferents. Neurosci Lett 259:62-64.

Hitosugi H, Kashiwazaki T, Ohsawa M, Kamei J (1999) Effects of Mexiletine on algogenic mediator-induced nociceptive responses in mice. Methods Find Exp Clin Pharmacol 21:409-413.

Hökfelt T, Elde R, Hohansson O, Luft R, Arimura A (1975) Immunohistochemical evidence for the presence of somatostatin, a powerful inhibitory peptide, in some primary sensory neurons. Neurosci Lett 1:231-235.

Inoue M, Nakajima S, Nakajima Y (1988) Somatostatin induces an inward rectification in rat locus coeruleus neurones through a pertussis toxin-sensitive mechanism. J Physiol (Lond) 407:177-198.

Kamei J, Kashiwazaki T, Taki K, Hitosugi H, Nagase H (1999) Algogenic mediator-induced nociceptive response in diabetic mice. Eur J Pharmacol 369:319-323.

Karalis K, Mastorakos G, Chrousos GP, Tolis G (1994) Somatostatin analogues suppress the inflammatory reaction in vivo. J Clin Invest 93:2000-2006.

Kayser V, Besson J-M, Guilbaud G (1988) Paradoxical effects of low doses of naloxone in experimental models of inflammatory pain. In: Progress in brain research (Fields HL, Besson J-M, eds), pp 301-312. Amsterdam: Elsevier.

Lembeck F, Donnerer J, Bartho L (1982) Inhibition of neurogenic vasodilatation and plasma extravasation by substance $\mathrm{P}$ antagonists, somatostatin and $\left[\mathrm{D}-\mathrm{MEt}^{2}, \mathrm{Pro}^{5}\right]$ enkephalinamide. Eur J Pharmacol 85:171-176.

Matucci-Cerinic M, Marabini S (1998) Somatostatin treatment for pain in rheumatoid arthritis: a double blind versus placebo study in knee involvement. Med Sci Res 16:233-234.

Maurer R, Gaehwiler BH, Buescher HH, Hill RC, Roemer D (1982) Opiate antagonistic properties of an octapeptide somatostatin analog. Proc Natl Acad Sci USA 79:4815-4817.

Meriney SD, Gray DB, Pilar GR (1994) Somatostatin-induced inhibition of neuronal $\mathrm{Ca}^{2+}$ current modulated by cGMP-dependent proteinkinase. Nature 369:336-339.

Meynadier J, Chrubasik J, Dubar M, Wunsch E (1985) Intrathecal somatostatin in terminally ill patients. A report of two cases. Pain 23:9-12.
Miletic V, Randic M (1982) Neonatal rat spinal cord slice preparation: postsynaptic effects of neuropeptides on dorsal horn neurons. Dev Brain Res 2:432-438.

Murase K, Nedeljkov V, Randic M (1982) The actions of neuropeptides on dorsal horn neurons in the rat spinal cord slice preparation: an intracellular study. Brain Res 234:170-176.

Paice JA, Penn RD, Kroin JS (1996) Intrathecal octreotide for relief of intractable nonmalignant pain: 5-year experience with two cases. Neurosurgery 38:203-207.

Patel YC (1992) General aspects of the biology and function of somatostatin. In: Somatostatin (Weil C, Miller EE, Thorner MO, eds), pp 1-16. Berlin: Springer.

Patel YC, Greenwood MT, Panetta R, Demchyshyn L, Nizik H, Srikant CB (1995) The somatostatin receptor family. Life Sci 57:1249-1265.

Plourde V, Lembo T, Shui Z, Parker J, Mertz H, Tache Y, Sytnik B, Mayer E (1993) Effects of the somatostatin analogue octreotide on rectal afferent nerves in humans. Am J Physiol 265:G742-G751.

Pugsley TA, Lippmann W (1978) Effect of somatostatin analogues and $17-\alpha$-dihydroequilin on rat brain opiate receptors. Res Commun Chem Pathol Pharmacol 21:153-157.

Randic M, Miletic V (1978) Depressant actions of methionineenkephalin and somatostatin in cat dorsal horn neurones activated by noxious stimuli. Brain Res 152:196-202.

Rios L, Jacob JJC (1983) Local inhibition of inflammatory pain by naloxone and its $N$-methyl quaternary analogue. Eur J Pharmacol 96:277-283

Sandkuhler J, Fu Q-G, Helmchen C (1990) Spinal somatostatin superfusion in vivo affects activity of cat nociceptive dorsal horn neurons: comparison with spinal morphine. Neuroscience 34:565-576.

Schepelmann K, Messlinger K, Schaible H-G, Schmidt RF (1995) The opioid antagonist naloxone does not alter discharges of nociceptive afferents from the acutely inflamed knee joint of the cat. Neurosci Lett 187:212-214

Schindler M, Selmer I-S, Helboe L, Hick GA, Jenkins D, Papotti M, Feniuk W, Humphrey PPA (1999) Localization of somatostatin receptors in the CNS and peripheral tissues. Regul Pept 80:136.

Schulz S, Schreff M, Schmidt H, Handel M, Przewlocki R, Hollt V (1998) Immunocytochemical localization of somatostatin receptor $\mathrm{SST}_{2}$ in the rat spinal cord and dorsal root ganglia. Eur $\mathrm{J}$ Neurosci 10:3700-3708.

Selmer I-S, Schindler M, Allen JP, Humphrey PPA, Emson PC (2000) Advances in understanding neuronal somatostatin receptors. Regul Pept 90:1-18.

Senaris RM, Schindler M, Humphrey PPA, Emson PC (1995) Expression of somatostatin receptor 3 mRNA in the motorneurones of the rat spinal cord, and the sensory neurones of the spinal ganglia. Mol Brain Res 29:185-190.

Siehler S, Hoyer D (1999) Characterization of human recombinant somatostatin receptors. II. Modulation of GTP $\gamma \mathrm{S}$ binding. Naunyn Schmiedebergs Arch Pharmacol 360:500-509.

Szolcsányi J, Helyes Z, Oroszi G, Nemeth J, Pintér E (1998a) Release of somatostatin and its role in the medication of the anti-inflammatory effect induced by antidromic stimulation of sensory fibres of rat sciatic nerve. Br J Pharmacol 123:936-942.

Szolcsányi J, Pintér E, Helyes Z, Oroszi G, Nemeth J (1998b) Systemic anti-inflammatory effect induced by counter-irritation through a local release of somatostatin from nociceptors. Br J Pharmacol 125:916-922.

Taddese A, Nah S-Y, McCleskey EW (1995) Selective opioid inhibition of small nociceptive neurons. Science 270:1366-1369.

Taura P, Planella V, Balust J, Beltran J, Anglada T, Carrero E, Burgues S (1994) Epidural somatostatin as an analgesic in upper abdominal surgery: a double-blind study. Pain 59:135-140.

ten Bokum AM, Hofland LJ, van Hagen PM (2000) Somatostatin and somatostatin receptors in the immune system: a review. Eur Cytokine Netw 11:161-176.

Tentler JJ, Hadcock JR, Gutierrez-Hartmann A (1997) Somatostatin acts by inhibiting the cyclic 3', 5'-adenosine monophosphate (cAMP)/ protein kinase A pathway, cAMP response element-binding protein (CREB) phosphorylation, and CREB transcription potency. Mol Endocrinol 11:859-866.

Terenius L (1976) Somatostatin and ACTH are peptides with partial antagonist-like selectivity for opiate receptors. Eur J Pharmacol 38:211-213.

Uhl GR, Tran V, Snyder SH, Martin JB (1985) Somatostatin receptors: distribution in rat central nervous system and human frontal cortex. J Comp Neurol 240:288-304.

Zimmermann M (1983) Ethical guidelines for investigations of experimental pain in conscious animals. Pain 16:109-110. 